\title{
Efeito da idade do desmame no desenvolvimento de novilhas de corte até os 14/15 meses de idade
}

\author{
Ricardo Zambarda Vaz ${ }^{1}$, José Fernando Piva Lobato²
}

\author{
1 Progepec Consultores Assoc. Ltda. \\ 2 Departamento de Zootecnia - Faculdade de Agronomia - UFRGS, Bolsista CNPq. Caixa Postal 15100: CEP : 90.001-970, Porto Alegre, RS.
}

RESUMO - Avaliou-se a influência do desmame precoce, em média aos 77 dias pós-parto, e do desmame convencional, em média aos 147 dias pós-parto, no desenvolvimento de novilhas de corte. Foram utilizadas 161 bezerras Braford, nascidas nos anos de 2004, 2005 e 2006. Após os desmames as bezerras foram mantidas em pastagens cultivadas de verão (Pennisetum americanum) e de inverno e primavera (Avena strigosa Schreb + Lolium multiflorum Lam). Foram avaliados os pesos corporais, ganhos de pesos médios diários e condição corporal a cada 28 dias. Houve interação entre idades de desmame e ano para peso corporal e ganho de peso. O desmame precoce não influenciou os pesos corporais, embora o peso corporal tenha sido menor aos 147 dias nos animais nascidos em 2005 e 2006. O ganho médio diário entre as idades de desmame foi similar nos três anos no desmame precoce $(0,538 ; 0,477$ e $0,472 \mathrm{~kg}$, respectivamente) e aumentou significativamente no desmame convencional com o avançar dos anos (0,516;0,704 e 1,040 kg, respectivamente). Na pastagem de Avena strigosa + Lolium multiflorum, o ganho médio diário foi similar entre idades de desmame. O peso no início do período reprodutivo no desmame precoce em $2004(283,4 \mathrm{~kg})$ foi maior que em $2005(260,7 \mathrm{~kg})$, enquanto no desmame convencional não houve diferença entre os anos (272,9 e $263,8 \mathrm{~kg}$, respectivamente). A condição corporal no início do período reprodutivo foi afetada pelo ano de observação. A idade da bezerra esteve positivamente correlacionada com os pesos ao desmame convencional $(r=0,510)$ e ao início do período reprodutivo $(\mathrm{r}=0,491)$. O desmame precoce e o convencional não inviabilizam o acasalamento das novilhas aos 14-/15 meses de idade.

Palavras-chave: condição corporal, desmame convencional, desmame precoce, ganho de peso.

\section{Effect of weaning age on beef heifers growth until 14/15 months of age}

ABSTRACT - The influence of the early weaning, on average 77 days after the birth, or the conventional weaning, on average 147 days on beef heifer development was evaluated. One hundred and sixty-one Braford calves, born in 2004, 2005 and 2006 were kept after weaning on cultivated summer (Pennisetum americanum) and winter/spring (Avena strigosa Schreb and Lolium multiflorum Lam) cultivated pastures. Body weight, daily Body weight gain and body condition were assessed every 28 days. There was interaction between weaning age and year for body weight and weight gain. Early weaning did not influence body weight but the body weight was smaller at 147 days in the animals born in 2005 and 2006. The avegage daily gain between the weaning ages was similar in the three years for early weaning $(0.538,0.477$ and $0.472 \mathrm{~kg}$, respectively), but increased significantly in the conventional weaning as the years progressed $(0.516,0.704$ and $1.040 \mathrm{~kg}$ respectively). The average daily weight gain on Avena strigosa + Lolium multiflorum pasture was similar for both treatments. The weight at the beginning of the reproduction period for early weaned heifers in $2004(283.4 \mathrm{~kg})$ was higher than in $2005(260.7 \mathrm{~kg})$, while for conventional weaning there was no difference between years $(272.9$ and $263.8 \mathrm{~kg}$, respectively). The body condition at the beginning of the reproduction period was affected by the year of observation. Calf age was positively correlated to weight at conventional weaning $(r=0.510)$ and beginning of the reproduction period $(r=0.491)$. Both weaning ages showed the possibility of mating beef heifers at $14 / 15$ months of age.

Key Words: body condition, conventional weaning, early weaning, weight gain

\section{Introdução}

A eficiência reprodutiva tem importância significativa nos indicadores de produtividade (Beretta et al., 2002). Assim, práticas de manejo influenciando o desempenho reprodutivo afetam os indicadores dos sistemas pecuários.
No Rio Grande do Sul, onde a base da alimentação dos rebanhos de cria normalmente são pastagens nativas, limitadas em quantidade e qualidade, a amamentação se torna energeticamente dispendiosa para as vacas de corte (Restle et al., 2001), que acabam recorrendo às suas reservas corporais para manter a produção de leite em nível não 
prejudicial ao desenvolvimento do bezerro. Além disso, o processo de amamentação é de baixa eficiência, pois consiste em converter forragem em leite e leite em tecidos corporais (Rovira, 1996).

O desmame precoce tem como objetivo principal aumentar a eficiência reprodutiva das fêmeas bovinas. Entretanto, todos os ganhos obtidos no desenvolvimento, acúmulo de reservas e melhor desempenho reprodutivo nas vacas submetidas ao desmame precoce não podem ser perdidos com a má-nutrição para as bezerras, comprometendo o sistema produtivo (Beretta et al., 2002; Almeida \& Lobato, 2004).

Ao reduzir a idade do primeiro acasalamento de novilhas, ocorrem reflexos consideráveis nas taxas de desfrute do rebanho (Pötter et al., 2000). Com a redução da idade ao primeiro acasalamento, pode-se melhorar a eficiência reprodutiva do rebanho por meio da maior e mais precoce pressão de seleção, diminuindo o intervalo entre gerações com retorno mais rápido dos investimentos.

O primeiro acasalamento aos 24 meses de idade continua sendo meta para os rebanhos comerciais brasileiros (Lobato, 1997). Assim, o manejo a ser dispensado às novilhas tem reflexo nos índices produtivos do rebanho de cria, (Pötter et al., 2000) e a idade do primeiro serviço das novilhas determinante na eficiência e rentabilidade da empresa rural (Beretta et al., 2002).

Entretanto, o primeiro acasalamento aos 14-15 meses de idade foi pouco estudado (Rocha \& Lobato, 2002), especialmente com bezerras desmamadas precocemente. Para o primeiro acasalamento aos 14-15 meses de idade, é necessário desenvolvimento que estimule o início precoce da atividade sexual da bezerra, com taxas adequadas de ganho de peso nos períodos pré e pósdesmame. Desta forma, avaliaram-se nesta pesquisa os reflexos da prática do desmame precoce no desenvolvimento de novilhas em um sistema com acasalamento aos 14-15 meses de idades.

\section{Material e Métodos}

O experimento foi realizado na Granja Itú, no município de Itaqui, região fisiográfica denominada fronteira oeste de estado do Rio Grande do Sul, a latitude $29^{\circ} 12^{\prime}$ sul e longitude $55^{\circ} 36^{\prime}$ oeste, no período de $9 / 2004$ a $11 / 2006$. O relevo da região é ondulado, com coxilhas de solos profundos, naturalmente ácidos com textura superficial média. O solo é classificado como latossolo vermelho distrófico (Embrapa, 1999) e o clima é subtropical, conforme classificação de Köppen (Moreno, 1961).
Foram utilizadas 161 bezerras Braford, distribuídas de acordo com a idade de desmame: desmame precoce desmame realizado em média aos 77 dias de idade (amplitude de 72 a 111 dias em 2004; 58 a 75 dias em 2005 e de 58 a 72 dias em 2006); e desmame convencional - desmame em média aos 147 dias de idade (amplitude de 141 a 179 dias em 2004; 100 a 145 dias em 2005 e de 93 a 153 dias em 2006).

Os nascimentos ocorreram nas primaveras de 2004 (7/9/2004 a 15/10/2004), 2005 (5/10/2005 a 1/12/2005) e 2006 (10/10/2006 a 25/11/2006) e as bezerras foram distribuídas da seguinte maneira: 38,39 e 27 bezerras do desmame precoce e 31,16 e 10 bezerras do desmame convencional, respectivamente, filhas de vacas primíparas no primeiro ano e das mesmas vacas no segundo e terceiro ano, frutos da repetição de prenhez, utilizando-se como fator de eliminação das vacas o diagnóstico de gestação negativo em qualquer dos anos. Como o trabalho se iniciou com vacas que pariram aos 3 anos (2004), e na sequência aos 4 (2005) e 5 anos (2006), os efeitos de ano de nascimento da bezerra e idade da vaca estiveram totalmente confundidos e, portanto, serão considerados nas análises como efeito conjunto. Os dados das fêmeas nascidas em 2006 foram incluídos somente até a idade do desmame convencional, período até o qual as fêmeas foram avaliadas.

As bezerras, enquanto ao pé das mães até as idades de desmame, foram mantidas em pastagem nativa com carga animal de $320 \mathrm{~kg}$ de peso vivo/ha no primeiro ano. Durante o segundo (10/12/2005 a 2/2/2006) e o terceiro período reprodutivo (15/12/2006 a 5/2/2007) de suas mães, as bezerras foram mantidas em pastagem de Brachiaria brizantha, cv Marandu, e Brachiaria humidicola, Rendle (schweick), respectivamente.

$\mathrm{Na}$ ocasião dos dois desmames, as bezerras foram mantidas em curral por dez dias, sendo que curtos períodos de pastejos horários começavam no quarto dia pós-desmame. Após esse período, as bezerras do desmame precoce foram mantidas durante o período de verão e outono em pastagem cultivada de milheto (Pennisetum americanum) com lotação de 8 bezerras/ha bezerras/ha e, nos meses de abril, pastejaram Braquiária brizanta com lotação de 4 bezerras/ha.

Todas as bezerras no período pós-desmame, desde os primeiros 10 dias em curral, até o início da pastagem de inverno, receberam suplementação balanceada com $18 \%$ de proteína bruta e $75 \%$ de NDT, formulada na propriedade com: farelo de soja, casca de soja, farelo de trigo, farelo de arroz integral, sal comum, calcário calcítico e mistura mineral na quantidade de $1 \%$ do peso vivo.

No inverno e na primavera, as bezerras pastejaram aveia (Avena strigosa Schreb) e azevém (Lolium 
multiflorum Lam) na lotação de 5 bezerras/ha até o término do ciclo das pastagens em novembro. No inverno de 2004 foi utilizada por 130 dias uma suplementação com casquinha de soja na quantidade de $0,4 \%$ do peso vivo. Os pastejos nos períodos de inverno-primavera encerraram em 14/11/2005 e 24/11/2006 para as novilhas nascidas em 2004 e 2005, respectivamente.

As estimativas da massa de forragem disponível foram realizadas pelo método comparativo (Haydock \& Shaw, 1975). As amostras foram analisadas quanto aos teores de proteína bruta $(\mathrm{PB})$ e fibra detergente neutra (FDN), estimados segundo técnicas descritas pela AOAC (1984) no Laboratório de Nutrição Animal da Faculdade de Agronomia da UFRGS.

As bezerras foram pesadas ao nascimento, nas datas dos desmames (precoce e convencional) e a cada 28 dias até o final do período de pastagens de ciclo hibernoprimaveril. Os ganhos de pesos diários (GMD) foram determinados pela diferença de peso entre as pesagens. Nas pesagens realizou-se a avaliação do escore de condição corporal (ECC; Lowman et al., 1973), com atribuição de valores de 1 a 5 , em que $1=$ muito magra e $5=$ muito gorda.

Durante o período experimental, as bezerras tinham livre acesso a uma mistura mineral com 60 ppm de fósforo composta de sal comum e ortofosfato bicálcico. Vacinações para o controle da febre aftosa, brucelose e leptospirose foram feitas nos períodos exigidos. O controle de endoparasitas foi realizado com dosificações estratégicas de vermífugos de amplo espectro e o de ectoparasitas (carrapatos, bernes e miíases) com produtos específicos.

$\mathrm{O}$ delineamento experimental foi o inteiramente casualizado com número diferente de repetições. As variáveis de pesos nas diferentes idades, o GMD e a condição corporal foram submetidos à análise de variância e ao teste F. O modelo estatístico referente utilizado para as análises foi:

$$
\mathrm{Y}_{\mathrm{ijk}}=\mu+\mathrm{T}_{\mathrm{i}}+\mathrm{A}_{\mathrm{j}}+\mathrm{T}^{*} \mathrm{~A}_{\mathrm{ij}}+\mathrm{IN}_{\mathrm{k}}+\Sigma_{\mathrm{ijk}}
$$

em que: $Y_{\mathrm{ijk}}=$ variáveis-dependentes (pesos, ganhos médios diários e condição corporal); $\mu=$ média de todas as observações; $T_{i}=$ efeito da i-ésima classe de idade de desmame, em que $\mathrm{i}=1$ (desmame precoce); ou 2 (desmame convencional); $\mathrm{A}_{\mathrm{j}}=$ efeito do $\mathrm{j}$-ésimo ano; $\mathrm{T}^{*} \mathrm{~A}_{\mathrm{ij}}=$ efeito da interação i-ésimo idade de desmame $\times$ efeito do j-ésimo ano; $\mathrm{IN}_{\mathrm{k}}=$ covariável idade do animal de ordem $\mathrm{j} ; \Sigma_{\mathrm{ijk}}=$ erro residual.

As análises foram realizadas com o auxílio do procedimento GLM e os dados foram analisados pelo programa estatístico SAS, versão 6.08 (SAS, 1997), adotando-se $5 \%$ como nível de significância máxima pelo teste " $\mathrm{t}$ ".

\section{Resultados e Discussão}

As massas de forragem e qualidade verificadas neste estudo nos diferentes tipos de pastagens nos anos de observação (Tabela 1) comprovam que seus valores qualitativos foram próximos aos observados em outros estudos realizados na Região Sul do Brasil (Freitas et al., 1976; Pilau \& Lobato, 2006), com pequenas diferenças, ocasionadas provavelmente pela diversidade de clima e fertilidade de solo de cada região.

Houve efeito da interação $(\mathrm{P}<0,05)$ idades de desmame $\times$ ano para as variáveis estudadas. Na ocasião do desmame precoce, os pesos das bezerras do desmame precoce nascidas em 2005 foi inferior $(\mathrm{P}<0,05)$ ao das nascidas nos demais anos (Tabela 2), enquanto o peso das bezerras do desmame convencional, por ocasião do desmame precoce não diferiu $(\mathrm{P}>0,05)$ entre anos. Aliás, por ocasião do desmame precoce, não se esperaria diferença entre as bezerras.

Tabela 1 - Massa de forragem (MF) e percentuais de proteína bruta (PB) e fibra detergente neutra (FDN) das pastagens utilizadas durante o período experimental

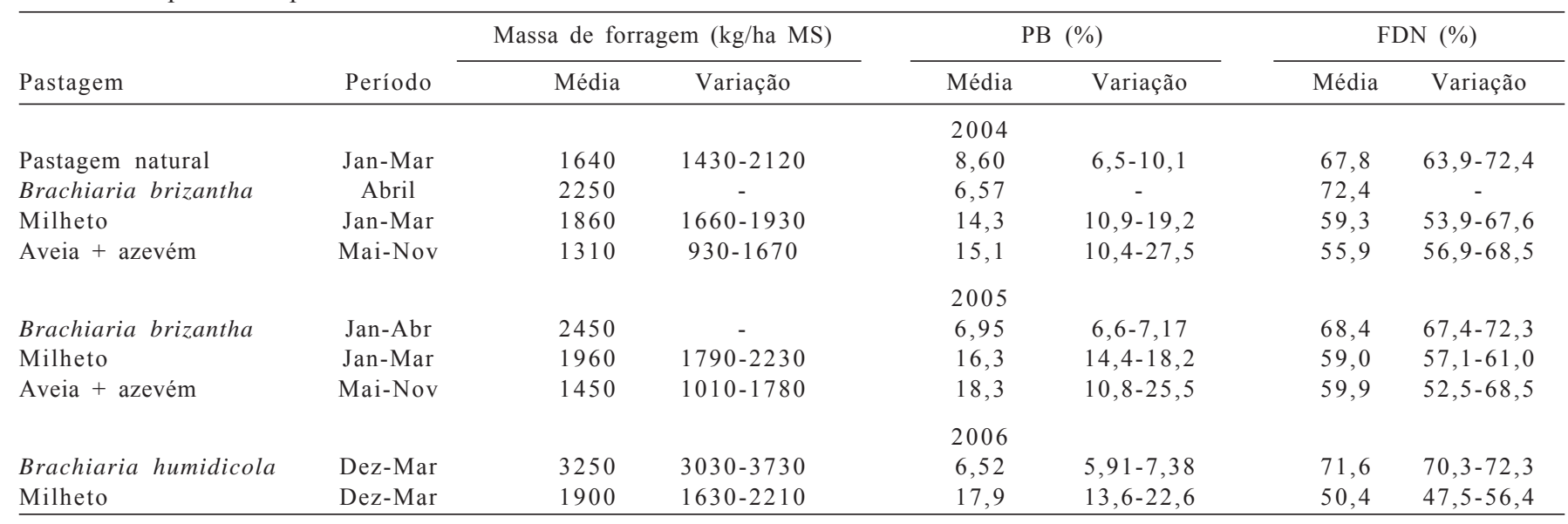


O peso das bezerras do desmame precoce por ocasião do desmame convencional foi inferior $(\mathrm{P}<0,05)$ no ano de 2005 , mas similar nos demais anos. Para as bezerras do desmame convencional, o peso foi superior em 2006 e não diferiu entre os demais anos. Na média dos três anos, os pesos foram 113,0 vs 126,3 kg para desmame precoce e desmame convencional, respectivamente, com diferença de $11,8 \%$ a favor dos animais mantidos ao pé da vaca $(\mathrm{P}>0,05)$. Em 2004, não houve diferença $(\mathrm{P}>0,05)$ no peso entre as duas idades de desmame. No ano de 2005, a diferença passou a ser significativa, representando $11,37 \%$ a favor do peso dos animais do desmame convencional e foi mais acentuada em $2006(26,0 \%)$.

No primeiro ano, não foi verificada diferença $(\mathrm{P}>0,05)$ no ganho médio diário (GMD DP-DC) das bezerras nas duas idades de desmame, mostrando que as condições de alimentação das bezerras do desmame precoce (pastagem de milheto associado à suplementação) proporcionaram condições adequadas de desenvolvimento às bezerras, similares às do desmame convencional mantidas junto às suas mães em campo nativo.

Para que o desmame precoce de bezerras com pesos iguais ou inferiores a $80 \mathrm{~kg}$ não comprometa seu desenvolvimento, é necessário disponibilizar alimentação capaz de suprir suas exigências nutricionais (Pascoal \& Vaz, 1997). Neste estudo, o desempenho similar verificado no ano de 2004 entre as bezerras dos diferentes tratamentos deveu-se ao fato de ter sido um ano atípico, com períodos de estiagem prolongados e chuvas abaixo do normal ( 70 e $14 \mathrm{~mm}$ durante os meses de janeiro e fevereiro, respectivamente), no intervalo entre as idades de desmame.

Houve decréscimo na quantidade e qualidade da pastagem nativa ofertada às vacas, devido à alta carga animal de $320 \mathrm{~kg} / \mathrm{ha}$, com reflexos negativos na produção de leite e no peso à desmama dos bezerros. A qualidade do campo nativo onde as bezerras permaneceram junto com suas mães foi baixa (Tabela 1), com valores de 8,60 e 67,83\% de PB e FDN, respectivamente. Nessas condições, fêmeas bovinas amamentando não têm bom desempenho reprodutivo (Almeida et al., 2002) e não oferecem a seus bezerros quantidade de leite suficiente para desenvolvimento adequado (Restle et al., 2004).

Resultados semelhantes aos encontrados nos anos de 2005 e 2006, demonstrando a superioridade em GMD dos animais amamentados por mais tempo em comparação a animais desmamados com menos idade foram observados por Almeida \& Lobato (2004). Bezerras desmamadas aos 170 dias vs bezerras desmamadas aos 91 dias mostraram superioridade de 15,61\% em peso vivo. Diferença semelhante, de $14,49 \%$ no peso ajustado aos 205 , dias também foi observada por Pötter et al. (2004) em bezerras de desmame aos 180 dias, quando comparadas às desmamadas aos 100 dias de idade.

O ganho médio diário no período entre os dois desmames das bezerras desmame precoce foi similar no primeiro, segundo e terceiro ano, 0,477; 0,538 e 0,472 kg, respectivamente. Por outro lado, nas bezerras do desmame convencional, ocorreu aumento praticamente linear no $\operatorname{GMD}(0,516 ; 0,704$ e $1,040 \mathrm{~kg}$, respectivamente). O aumento no GMD das bezerras do desmame convencional ao longo dos anos deve estar associado à mais alta produção de leite das vacas e, embora esta característica não tenha sido avaliada, sabe-se do aumento dessa até a idade adulta da vaca (Restle et al., 2001; Vieira et al., 2006; Cerdótes et al., 2004 b). Outro aspecto pode estar relacionado ao tipo de pastagem, que variou nos três anos durante o período de lactação das bezerras do desmame convencional (Tabela 1), influenciando não apenas na produção de leite das mães, mas também a disponibilidade e a qualidade do pasto para as bezerras. Conforme comentado anteriormente, o efeito de ano inclui vários aspectos (clima, idade da vaca e tipo do pasto) e não foi possível neste experimento separar esses efeitos.

Tabela 2 - Pesos vivos médios no desmame precoce, no desmame convencional e ganhos médios diários no período entre o desmame precoce e desmame convencional nos anos analisados

\begin{tabular}{lccccc}
\hline Tipo de desmames & Ano & Número & $\begin{array}{c}\text { Peso desmame } \\
\text { precoce, kg }\end{array}$ & $\begin{array}{c}\text { Peso desmame } \\
\text { convencional, kg }\end{array}$ & $\begin{array}{c}\text { GMD desmame precoce }- \\
\text { desmame convencional, kg }\end{array}$ \\
\hline Desmame precoce & 2004 & 38 & $83,4 \mathrm{a}$ & $115,9 \mathrm{~b}$ & $0,538 \mathrm{c}$ \\
& 2005 & 39 & $77,3 \mathrm{~b}$ & $107,3 \mathrm{c}$ & $0,477 \mathrm{c}$ \\
& 2006 & 27 & $84,0 \mathrm{a}$ & $115,7 \mathrm{~b}$ & $0,472 \mathrm{c}$ \\
Desmame convencional & Média & & 81,6 & 113,0 & 0,496 \\
& 2004 & 31 & $82,5 \mathrm{ab}$ & $113,6 \mathrm{~b}$ & $0,516 \mathrm{c}$ \\
& 2005 & 16 & $79,2 \mathrm{ab}$ & $119,5 \mathrm{~b}$ & $1,040 \mathrm{~b}$ \\
& 2006 & 10 & $77,1 \mathrm{ab}$ & $145,8 \mathrm{a}$ & 0,752 \\
& Média & & 79,6 & 126,3 & 32,17 \\
\hline
\end{tabular}

Médias na mesma coluna seguidas por letras diferentes diferem $(\mathrm{P}<0,05)$ pelo teste $\mathrm{t}$. 
A média dos três anos para o GMD no período entre os dois desmames foi de $0,496 \mathrm{vs} 0,752 \mathrm{~kg}$, respectivamente, para desmame precoce e desmame convencional. Nos anos de 2005 e 2006, o GMD dos animais do desmame convencional superou em 47,6 e 120,3\%, respectivamente, o ganho de peso dos animais desmame precoce. Essa diferença na média é superior aos $54,67 \%$ encontrados por Restle et al. (1999) em bezerros dos 3 aos 7 meses. Os ganhos de peso observados neste experimento são superiores aos encontrados por Moraes \& Lobato (1993), ao trabalharem com animais desmamados aos sete $(0,620 \mathrm{~kg})$ ou aos 5 meses de idade $(0,350 \mathrm{~kg})$. Almeida \& Lobato (2004) também verificaram ganhos de pesos inferiores para bezerras desmamadas aos 91 dias $(0,381 \mathrm{~kg})$ em relação às desmamadas aos $170 \operatorname{dias}(0,603 \mathrm{~kg})$.

O menor ganho de peso geralmente verificado para os animais do desmame precoce (Simeone \& Lobato, 1998; Restle et al., 1999; Almeida \& Lobato, 2004; Pötter et al., 2004) no período imediato ao desmame deve-se ao estresse do desmame e à submissão a uma alimentação na qual o seu aparelho digestivo não está ainda completamente desenvolvido e adaptado. Por conseguinte, os bezerros não retiram da alimentação disponibilizada a quantidade de nutrientes suficientes para manter os ganhos de peso que apresentariam ao pé da vaca, tornando-se mais evidente quando o pasto disponível é de baixa qualidade.

A importância do leite no desenvolvimento dos bezerros fica evidente em trabalho realizado por Ribeiro \& Restle(1991), que observaram que a produção de leite da vaca é responsável por $56 \%$ da variação de peso dos bezerros do nascimento aos 235 dias de idade. Alencar et al. (1996) também concluíram que a produção de leite é uma importante fonte de variação no peso à desmama e nos ganhos de peso do nascimento à desmama, com correlações de 0,64 e de 0,67 , respectivamente.

Outros autores verificaram que em condições de excesso de carga animal, ocorreram menor desempenho reprodutivo (Simeone \& Lobato, 1996; Fagundes et al., 2003), atraso nas concepções dentro do período reprodutivo (Pötter \& Lobato, 2004), menor produção de leite pelas vacas (Quadros \& Lobato, 1997) e menor peso à desmama dos bezerros (Quadros \& Lobato, 1997; Simeone \& Lobato, 1998).

Neste estudo, associado a este fato, as vacas no ano de 2004 eram primíparas aos três anos, com menores produções de leite e, devido ao seu crescimento (Freetly, 1999) tiveram as suas exigências aumentadas (Rovira, 1996; Restle et al., 2001), contribuindo para o menor desempenho das bezerras. Lobato \& Vaz (2006) enfatizaram as altas exigências nutricionais das vacas, independentemente do ciclo reprodutivo, pois ocorrem sobreposições de suas exigências nutricionais de mantença, crescimento, lactação e reprodução durante o ano em produção.

O desempenho das bezerras no intervalo entre o desmame precoce e o convencional teve efeito de ano, conforme já comentado. Nos anos de 2005 e de 2006, as bezerras do desmame convencional tiveram ganho médio diário de $0,872 \mathrm{~kg}$, superior aos $0,475 \mathrm{~kg}$ das do desmame precoce. Esses ganhos de peso são superiores aos encontrados por Moraes e Lobato (1993) em animais desmamados aos $7(0,620 \mathrm{~kg})$ ou aos 5 meses de idade $(0,350 \mathrm{~kg})$. Almeida \& Lobato (2004) também verificaram ganhos de peso inferiores para bezerras desmamadas aos 91 dias em comparação às desmamadas aos 170 dias de idade $(0,381$ e $0,603 \mathrm{~kg}$, respectivamente).

Variações fisiológicas ocorrem com o avanço da idade, proporcionando desempenhos máximos com a maturidade do animal (Cobuci et al., 2000). Restle et al. (2001) e Cerdótes et al. (2004b) observaram maiores produções de leite de vacas de corte entre os 5 e 7 anos de idade, com maior peso dos bezerros ao desmame (Vieira et al., 2005).

Simeone et al. (1997), trabalhando com bezerros desmamados aos 78 ou 141 dias pós-parto, verificaram ganhos de pesos inferiores de $243 \mathrm{~g}$ para animais do desmame precoce contra $590 \mathrm{~g}$ para animais desmame convencional. Esses autores verificaram que aos 15 meses de idade os animais desmamados aos 78 dias eram inferiores, em peso, aos animais desmamados aos 141 dias $(233,1 \mathrm{vs} 249,6 \mathrm{~kg}$, respectivamente).

No período após o desmame em idade convencional (Tabela 3), as bezerras das duas idades de desmame permaneceram nas mesmas condições de alimentação, em final de ciclo de pastagem de milheto durante o mês de março e em pastagem de braquiária brizanta durante o mês de abril, sendo o ganho de peso médio diário das bezerras do desmame precoce superior $(\mathrm{P}<0,05)$. Os menores ganhos de peso verificados nos animais do desmame convencional, em parte são atribuídos ao estresse do desmame, o qual, independemente da idade em que é realizado, pode causar prejuízos momentâneos no desenvolvimento animal.

Os ganhos de peso observados neste estudo estão acima da média dos demais experimentos, comprovando a possibilidade de uma alimentação de melhor qualidade proporcionar melhores ganhos nas bezerras. Almeida \& Lobato (2004) observaram que o campo nativo, no período pós-desmame, não é uma alimentação adequada para bezerras de corte suprirem as suas exigências nutricionais para bons ganhos de peso, pois não permite aos animais manifestarem o seu potencial de crescimento. Nestas condições os autores observaram ganhos de 6,4 e 4,6 kg 
Tabela 3 - Pesos vivos médios e ganhos médios diários (GMD) em março e abril após o desmame a idade convencional nos dois tratamentos, nos diferentes anos

\begin{tabular}{|c|c|c|c|c|c|c|}
\hline \multirow{2}{*}{ Tipo dedesmame } & \multirow[b]{2}{*}{ Ano } & \multirow[b]{2}{*}{ Número } & \multicolumn{4}{|c|}{ Período pós-desmame } \\
\hline & & & Março (kg) & GMD Março (kg) & Abril $(\mathrm{kg})$ & GMD abril $(\mathrm{kg})$ \\
\hline \multirow[t]{3}{*}{ Desmame precoce } & 2004 & 38 & $141,0 \mathrm{a}$ & $0,814 \mathrm{a}$ & $159,7 \mathrm{a}$ & $0,668 \mathrm{a}$ \\
\hline & 2005 & 39 & $122,7 \mathrm{~b}$ & $0,457 \mathrm{~b}$ & $133,7 \mathrm{c}$ & $0,354 \mathrm{~b}$ \\
\hline & Média & & $131,9 \mathrm{~A}$ & $0,635 \mathrm{~A}$ & $146,7 \mathrm{~A}$ & $0,511 \mathrm{~A}$ \\
\hline \multirow[t]{4}{*}{ Desmame convencional } & 2004 & 31 & $126,7 \mathrm{~b}$ & $0,383 b$ & $145,9 b$ & $0,689 \mathrm{a}$ \\
\hline & 2005 & 16 & $128,1 \mathrm{~b}$ & $0,223 \mathrm{c}$ & $139,7 b$ & $0,374 b$ \\
\hline & Média & & $127,4 \mathrm{~A}$ & $0,303 \mathrm{~B}$ & $142,8 \mathrm{~A}$ & $0,530 \mathrm{~A}$ \\
\hline & $\mathrm{CV}(\%)$ & & 13,7 & 33,5 & 13,3 & 24,9 \\
\hline
\end{tabular}

Valores seguidos das mesmas letras na mesma coluna não diferem $(\mathrm{P}>0,05)$ entre si pelo teste $\mathrm{t}$.

$\mathrm{Na}$ mesma coluna diferem entre médias das idades de desmame pelo teste $\mathrm{F}$.

para os desmames precoce e convencional, respectivamente, no período de 26/3 a 25/5/1999.

Muehlmann et al. (1997) verificaram diferentes desempenhos de bezerras desmamadas aos 3 meses de idade submetidas à alimentação exclusiva de pastagem nativa com $34,28 \%$ de digestibilidade e observaram que as bezerras praticamente mantiveram o peso, com ganho médio diário de $12 \mathrm{~g} /$ dia, enquanto, nas bezerras mantidas em capim-bermuda com $50,13 \%$ de digestibilidade, o ganho foi de $314 \mathrm{~g}$.

De maio a novembro (período de inverno/primavera), as bezerras permaneceram em pastagem cultivada de aveia e azevém. Nesta fase não houve diferença no ganho de peso entre as idades de desmame, com média de $0,619 \mathrm{~kg} / \mathrm{animal} /$ dia nos dois anos (Tabela 4). Esses ganhos são considerados razoáveis. Diversos estudos com a mesma categoria animal sob pastejo contínuo comprovam ganhos na faixa de 0,600 a $0,900 \mathrm{~kg}$, dependendo do histórico dos animais, do período de utilização e do início do pastejo, em decorrência dos ganhos compensatórios (Roso \& Restle, 2000; Frizzo et al., 2003; Rocha et al., 2003; Pilau \& Lobato, 2006).

Apesar do estresse e da perda de peso após o manejo de desmama (Simeone \& Lobato, 1998; Restle et al., 1999; Almeida \& Lobato, 2004), houve ganho compensatório nos períodos posteriores a esse estresse (Simeone \& Lobato,
1998; Restle et al., 1999), embora algumas vezes esse ganho não tenha sido significativo (Almeida \& Lobato, 2004; Cerdótes et al., 2004a).

Pilau \& Lobato (2006) observaram também capacidade de recuperação de peso vivo entre animais de diferentes rebanhos e atribuíram essa recuperação à interação da condição alimentar $x$ crescimento compensatório $\times$ seleção genética. Essa maior eficiência e o maior ganho de peso se devem provavelmente ao maior consumo de energia metabolizável, que foi superior às exigências de mantença (Poppi \& McLennan, 1995).

O peso atingido por novilhas entre os 13 e 14 meses de idade é influenciado, entre outros fatores, pelo seu peso ao desmame e pelo nível alimentar ao qual serão submetidas no período pós-desmame (Beretta \& Lobato, 1998), o qual é determinante do ganho de peso nesta fase. Neste estudo o ganho de peso no período após o desmame convencional teve influência da idade de desmame $(\mathrm{P}<0,05)$ das bezerras $(0,617$ vs $0,582 \mathrm{~kg}$, para os desmames precoce e convencional, respectivamente), pois houve ganho compensatório nos animais desmamados precocemente. Resultados semelhantes foram observados por Almeida \& Lobato (2004) e Pötter et al. (2004).

Embora as bezerras tenham apresentado diferenças no GMD durante o período pós-desmame à idade convencional

Tabela 4 - Pesos vivos médios ao início e ao final da pastagem de aveia e azevém e ganhos médios diários (GMD) durante e após o desmame em idade convencional

\begin{tabular}{|c|c|c|c|c|c|c|}
\hline \multirow[t]{2}{*}{ Tipo de desmame } & \multirow[b]{2}{*}{ Ano } & \multirow[b]{2}{*}{ Número } & \multicolumn{4}{|c|}{ Período inverno/primavera (Pastagem cultivada) } \\
\hline & & & $\begin{array}{l}\text { Peso inicial, } \\
\mathrm{kg}\end{array}$ & $\begin{array}{l}\text { Peso final, } \\
\mathrm{kg}\end{array}$ & $\begin{array}{l}\text { GMD Inverno/ } \\
\text { primavera, } \mathrm{kg}\end{array}$ & $\begin{array}{c}\text { GMD desmame } \\
\text { convencional - final, } \mathrm{kg}\end{array}$ \\
\hline \multirow[t]{3}{*}{ Desmame precoce } & 2004 & 37 & $159,7 \mathrm{a}$ & $283,4 \mathrm{a}$ & $0,627 \mathrm{a}$ & $0,658 \mathrm{a}$ \\
\hline & 2005 & 39 & $133,7 \mathrm{c}$ & $260,7 b$ & $0,610 \mathrm{a}$ & $0,578 b$ \\
\hline & Média & & $146,7 \mathrm{~A}$ & $272,1 \mathrm{~A}$ & $0,619 \mathrm{~A}$ & $0,617 \mathrm{~A}$ \\
\hline \multirow[t]{4}{*}{ Desmame convencional } & 2004 & 29 & $145,9 b$ & $272,9 \mathrm{a}$ & $0,640 \mathrm{a}$ & $0,621 \mathrm{a}$ \\
\hline & 2005 & 16 & $139,7 \mathrm{bc}$ & $263,8 \mathrm{a}$ & $0,598 \mathrm{a}$ & $0,544 \mathrm{c}$ \\
\hline & Média & & $142,8 \mathrm{~A}$ & $268,4 \mathrm{~A}$ & $0,619 \mathrm{~A}$ & $0,582 \mathrm{~B}$ \\
\hline & CV $(\%)$ & & 13,3 & 10,0 & 13,9 & 11,9 \\
\hline
\end{tabular}

Valores seguidos das mesmas letras, na mesma coluna, não diferem $(\mathrm{P}>0,05)$ entre si pelo teste $\mathrm{t}$.

$\mathrm{Na}$ mesma coluna diferem entre médias das idades de desmame pelo teste $\mathrm{F}$. 
(147 dias) até os 14 meses de idade, ao final do período experimental, o peso não apresentou diferenças $(\mathrm{P}>0,05)$ na comparação entre as duas idades de desmame. Normalmente nos trabalhos envolvendo diferentes idades de desmame não ocorre diferença nos pesos entre os 12 a 13 meses de idade, como observado neste estudo, sendo que os animais desmamados precocemente já realizaram a compensação da restrição sofrida no período imediatamente após o desmame precoce (Restle et al., 1999; Pötter et al., 2004).

Os pesos de 272,1 kg e 268,4 kg para desmame precoce e desmame convencional, respectivamente, significam $60 \%$ do peso adulto do rebanho em estudo $(450 \mathrm{~kg}$ por ocasião da venda ao abate) viabilizando desta forma a utilização do acasalamento com início aos 14 de meses de idade de novilhas de corte. Segundo o NRC (1996), novilhas Bos taurus e Bos indicus devem ter no mínimo de 60 e $65 \%$ do seu peso adulto, respectivamente, para que possam alcançar a puberdade e conceber.

Observando-se as curvas de crescimento das novilhas de acordo com a idade de desmame e o ano (Figura 1), verifica-se que, independentemente da idade de desmame e do ano de nascimento, o comportamento foi similar entre os anos, com maior desenvolvimento para as novilhas nascidas em 2004.

Mesmo com a maior permanência nas pastagens de inverno-primavera (10 dias) das bezerras nascidas em 2005, este período não foi suficiente para chegarem com peso similar ao das nascidas em 2004. Esse fato, em sistemas de ciclo curto com o primeiro período de acasalamentoaos 14 meses, é fundamental para uma boa resposta reprodutiva.

Esse menor desenvolvimento das novilhas durante o ano de 2005, 15,9 $\mathrm{kg}$ mais leves que as novilhas no ano de
2004 (Tabela 4), deve-se especialmente aos 25 dias de idade a menos, em média, à idade de 14 meses. Este fato salienta a importância de evitar o atraso no nascimento das bezerras (Osoro, 1986), principalmente quando se intensifica o sistema de criação, com o objetivo de acasalamento de novilhas entre os 13 aos 15 meses de idade.

O desenvolvimento das novilhas e seu desempenho reprodutivo são extremamente importantes na produtividade de sistemas de ciclos completos (Pötter et al., 2000; Beretta et al., 2001; Vieira et al., 2006). Novilhas de reposição, além de manterem um rebanho estável, se oriundas de programas mensuráveis de melhoramento genético, devem ser geneticamente superiores às suas mães.

A análise da condição corporal é um bom indicador do desenvolvimento muscular e da deposição de gordura subcutânea, os quais têm correlação com o desempenho reprodutivo das novilhas (Lemenager et al., 1980).

Não houve diferenças de condição corporal entre as idades de desmame dentro dos anos de avaliação. No entanto, verificou-se (Figura 2) variação da condição corporal entre os anos de avaliação, com superioridade para o ano de 2004, o que se deve, em parte, à suplementação utilizada para esses animais $(0,4 \%$ do peso vivo com casquinha de soja) durante o período da pastagem de aveia + azevém, a qual não se manifestou em ganho de peso, mas devido ao maior aporte de energia em deposição de gordura corporal.

A suplementação pode alterar as relações de qualidade e quantidade de consumo de forragem conforme seus efeitos aditivos ou substitutivos (Pilau \& Lobato, 2006). Neste experimento deve ter ocorrido efeito aditivo substitutivo no consumo de MS, determinando nos animais do ano de

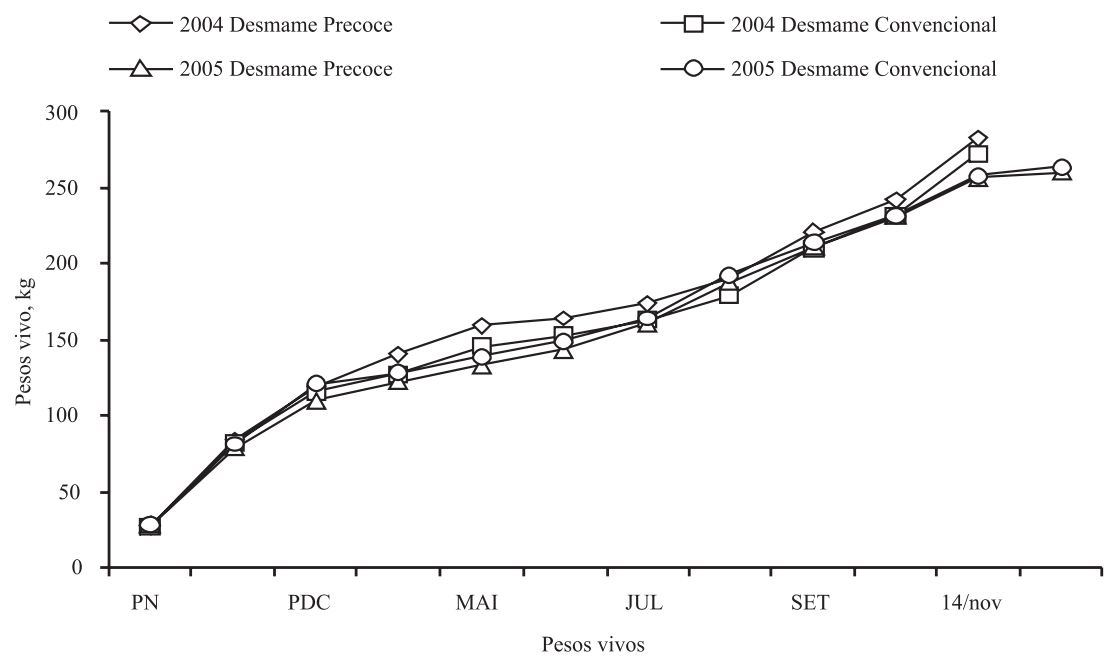

Figura 1 - Evolução do peso vivo das novilhas do nascimento aos 14 meses de idade de acordo com a idade de desmame e com o ano de observação. 


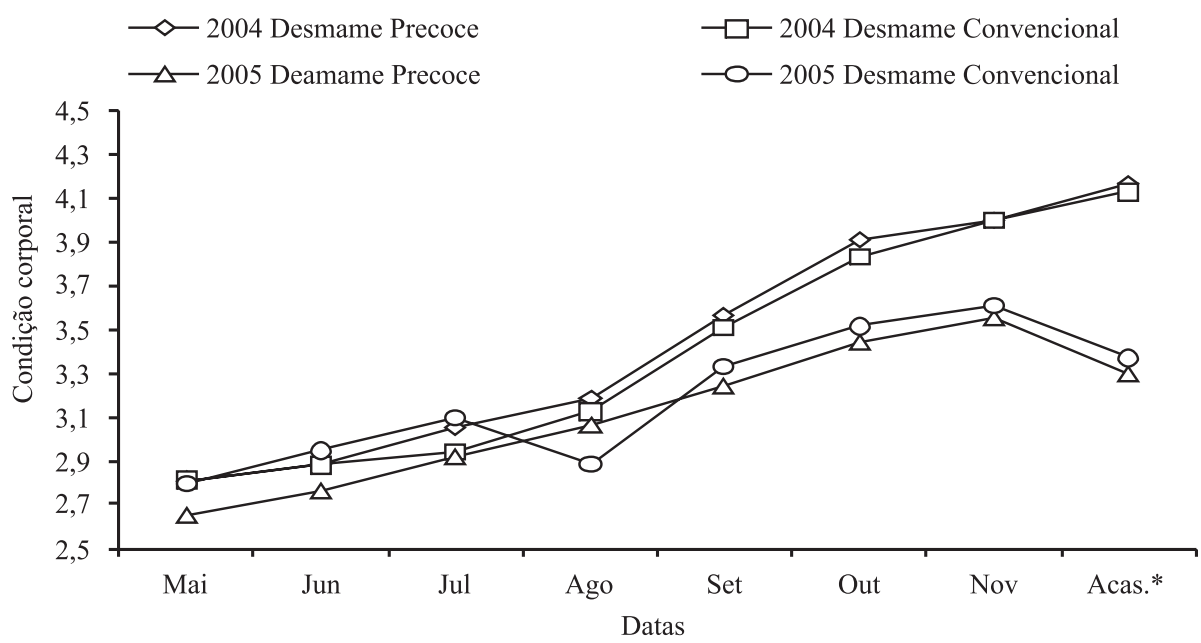

Figura 2 - Evolução da condição corporal (CC) das novilhas desde 01/05/2005 e 01/05/2006 aos 14 meses de idade, de acordo com a idade de desmame e ano de observação.

2004 maior deposição de gordura corporal, sem diferença no peso final entre os anos de observação (Tabela 4).

As médias de condição corporal ao final da pastagem de aveia e azevém nos anos de 2004 e de 2005 foram de 4,14 e 3,33 pontos, respectivamente, valores compatíveis para bons índices de cio e prenhez de novilhas. Frizzo et al. (2003), trabalhando em condições semelhantes de pastagem cultivada de inverno com diferentes níveis de suplementação, observaram crescimento linear da condição corporal, correlacionando-se positivamente com a manifestação de cios. Rocha \& Lobato (2002) analisaram novilhas com condição corporal de 3,5 pontos e obtiveram uma taxa de prenhez média de 59,39\%, independentemente do sistema de alimentação ao qual foram submetidas às novilhas durante a recria.

Independentemente da idade de desmame, quando avaliados os anos de observação, verifica-se que a relação PV/CC no ano de 2004 com a utilização de suplementação foi de $90 \mathrm{~kg}$ /ponto de condição corporal. No ano de 2005 , ano em que as novilhas permaneceram exclusivamente em pastagem cultivada de inverno, a relação $\mathrm{PV} / \mathrm{CC}$ foi de $205 \mathrm{~kg} /$ ponto de CC. Essas relações estão de acordo com as estimativas realizadas por Pilau et al. (2005) e Pilau \& Lobato (2006), que verificaram a mesma tendência e atribuíram esses resultados ao maior aporte energético promovido pela suplementação, com grande influência sobre a composição do ganho de peso e acelerando a deposição de gordura. Esses autores relacionaram o alto valor desta relação em bezerras de corte à grande necessidade de deposição de tecido muscular durante seu crescimento.

As variáveis de peso do desmame à idade convencional e peso ao início do período reprodutivo foram altamente correlacionadas $(r=0,775)$ e relacionaram-se, também positivamente, com o ganho de peso durante o período pós-desmame até $\mathrm{o}$ início do período reprodutivo $(\mathrm{r}=0,281$; Tabela 5).

A alta correlação entre o peso ao desmame (DC) e o peso no início do período reprodutivo (PIR) comprova que as novilhas mais pesadas e mais velhas ao desmame

Tabela 5 - Coeficientes de correlação entre pesos vivos no desmame precoce (DP), no desmame a idade convencional (DC), peso (PIR) e condição corporal (CCIPR) ao início do período reprodutivo, ganho de peso médio diário (GMD) entre o desmame a idade convencional e o início do período reprodutivo e a idade das novilhas desmamadas em diferentes idades

\begin{tabular}{|c|c|c|c|c|c|}
\hline Desman & ne convencional & $\begin{array}{l}\text { Peso ao início do } \\
\text { período reprodutivo }\end{array}$ & $\begin{array}{l}\text { Condição corporal ao início } \\
\text { do período reprodutivo }\end{array}$ & $\begin{array}{l}\text { Ganho } \\
\text { médio diário }\end{array}$ & Idade $^{1}$ \\
\hline Desmame precoce & $0,690 * *$ & $0,693 * *$ & $0,512 * *$ & $0,280 * *$ & $0,470 * *$ \\
\hline Desmame convencional & - & $0,775 * *$ & $0,549 * *$ & $0,281 * *$ & $0,510 * *$ \\
\hline Peso ao início do período reprodutivo & - & - & $0,615 * *$ & $0,820 * *$ & $0,491 * *$ \\
\hline $\begin{array}{l}\text { Condição corporal ao } \\
\text { início do período reprodutivo }\end{array}$ & - & - & - & $0,520 * *$ & $0,640 * *$ \\
\hline Ganho médio diário & - & - & - & - & $0,299 * *$ \\
\hline
\end{tabular}

** $\mathrm{P}<0,01$

${ }^{1}$ Idade das novilhas ao início do período reprodutivo. 
são mais precoces na manifestação da puberdade e as que ficam prenhes no início do período reprodutivo. Pilau \& Lobato (2006), no entanto, não observaram correlação significativa entre o peso inicial e o ganho de peso no período pós-desmame.

\section{Conclusões}

Bezerras desmamadas precocemente, aos 77 dias de idade, quando alimentadas adequadamente, possuem desenvolvimento semelhante ao de bezerras amamentadas até os 147 dias de idade. Em sistemas de ciclo completo intensivo e desmame precoce, é possível atingir desenvolvimento adequado de novilhas para acasalamento entre os 14 e 15 meses de idade por meio de bom manejo nutricional. Novilhas mais pesadas aos 14 e 15 meses de idade são mais pesadas ao desmame e esse maior peso também depende do ganho de peso das bezerras entre o desmame e esta idade.

\section{Referências}

ALENCAR, M.M.; TULIO, R.R.; CRUZ, G.M. et al. Produção de leite da vaca e desenvolvimento do bezerro em gado de corte. Revista Brasileira de Zootecnia, v.25, n.1, p.92-101, 1996.

ALMEIDA, L.S.P.; LOBATO, J.F.P.; SCHENKEL, F.S. Data de desmame e desempenho reprodutivo de vacas de corte. Revista Brasileira de Zootecnia, v.31, n.3, p.1223-1229, 2002.

ALMEIDA, L.S.P.; LOBATO, J.F.P. Efeito da idade de desmame e suplementação no desenvolvimento de novilhas de corte. Revista Brasileira de Zootecnia, v.33, n.6, p.2086-2094, 2004 (supl.2).

ASSOCIATION OF OFFICIAL ANALYTICAL CHEMITS - AOAC. Official methods of analysis. 14.ed. Washington, D.C.: AOAC Internacional, 1984. 1141p.

BERETTA, V.; LOBATO, J.F.P. Sistema "Um Ano" de produção de carne: Avaliação de estratégias alternativas de alimentação hibernal de novilhas de reposição. Revista Brasileira de Zootecnia, v.27, n.1, p.157-163, 1998.

BERETTA, V.; LOBATO, J.F.P.; MIELITZ NETO, C.G.A. Produtividade e eficiência biológica de sistemas de produção de gado de corte de ciclo completo no Rio Grande do Sul. Revista Brasileira de Zootecnia, v.31, n.2, p.991-1001, 2002 (supl.)

BERETTA, V.; LOBATO, J.F.P.; MIELITZ NETO, C.G.A. Produtividade e eficiência biológica de sistemas Pecuários de cria diferindo na idade das novilhas ao primeiro parto e na taxa de natalidade do rebanho no Rio Grande de Sul. Revista Brasileira de Zootecnia, v.30, n.4, p.1278-1286, 2001.

CERDÓteS, L.; RESTle, J.; ALVES FILHO, D.C. et al. Desempenho de bezerros de corte filhos de vacas submetidas a diferentes manejos alimentares, desmamados aos 42 ou 63 dias de idade. Revista Brasileira de Zootecnia, v.33, n.3, p.597-609, $2004 \mathrm{a}$.

CERDÓTES, L.; RESTLE, J.; ALVES FILHO, D.C. et al. Produção e composição do leite de vacas de quatro grupos genéticos submetidas a dois manejos alimentares no período de lactação. Revista Brasileira de Zootecnia, v.33, n.3, p.610-622, 2004b.

COBUCI, J.A.; EUCLYDES, R.F.; VERNEQUE, R.S. et al. Curva de lactação na raça guzerá. Revista Brasileira de Zootecnia, v.29, n.5, p.1332-1339, 2000.
EMPRESA BRASILEIRA DE PESQUISA AGROPECUÁRIA EMBRAPA. Sistema brasileiro de classificação de solos. Brasília: Embrapa Cerrados; Rio de Janeiro: Centro Nacional de Pesquisa de Solos, 1999. 412p.

FAGUNDES, J.I.B.; LOBATO, J.F.P.; SCHENKEL, F.S. Efeito de duas cargas animais em campo nativo e de duas idades a desmama no desempenho de vacas de corte primíparas. Revista Brasileira de Zootecnia, v.32, n.6, p.1722-1731, 2003 (supl.1).

FREETLY, H.C. The replacement heifer and the primiparous cow. In: REUNIÃO ANNUAL DA SOCIEDADE BRASILEIRA DE ZOOTECNIA, 36., 1999, Porto Alegre. Anais... Porto Alegre: Sociedade Brasileira de Zootecnia, 1999. p.241-249.

FREITAS, E.A.; LOPEZ, J.; PRATES, E.R. Produtividade de matéria seca, proteína digestível, e nutrientes digestíveis totais em pastagem nativa do Rio Grande do Sul. Anuário Técnico IPZFO, v.3, p.454-515, 1976.

FRIZZO, A.; ROCHA, M.G.; RESTLE, J. et al Suplementação energética na recria de bezerras de corte mantidas em pastagem de inverno. Revista Brasileira de Zootecnia, v.32, n.3, p.643-652, 2003.

HAYDOCK, K.P.; SHAW, N.H. The comparative yield method for stimating dry matter yield of pasture. Australian Journal of Experimental Agriculture and Animal Husbandry, v.15, n.76, p.663-670, 1975.

LEMENAGER, R.P.; SMITH, W.H.; MARTIN, T.G. et al. Effects of winter and summer energy levels on heifers growth and reproductive performance. Journal of Animal Science, v.51, n.4, p.837-842, 1980 .

LOBATO, J.F.P. Sistema intensivos de produção de carne bovina: 1. Cria. In: SIMPÓSIO SOBRE PECUÁRIA DE CORTE, 4., 1997, Piracicaba. Anais... Piracicaba: Fundação de Estudos Agrários Luiz de Queiroz, 1997. p.161-204.

LOBATO, J.F.P.; VAZ, R.Z. O manejo do gado de cria no campo nativo. In: SIMPÓSIO DE FORRAGEIRAS E PRODUÇÃO ANIMAL - Ênfase: Importância e potencial produtivo da pastagem nativa, I., 2006, Porto Alegre. Anais... Porto Alegre: ULBRA, 2006. 162p.

LOWMAN, B.G.; SCOTT, N.; SOMERVILLE, S. Condition scoring beef cattle. Edinburgh: East of Scotland College of Agriculture, 1973. 8p.

MORAES, A.A.S.; LOBATO, J.F.P. Efeito de duas idades de desmame no desenvolvimento de terneiros de corte. Revista Brasileira de Zootecnia, v.22, n.6, p.885-892, 1993

Moreno, J.A. Clima do Rio Grande do Sul. Porto Alegre: Secretaria da Agricultura, 1961. 41p.

MUEHLMANN, L.D.; ROCHA, M.G.; RESTLE, J. Utilização de pastagens de estação quente com bovinos desmamados precocemente. Revista Brasileira de Zootecnia, v.26, n.3, p.384-389, 1997.

NATIONAL RESEARCH COUNCIL - NRC. Nutrient requeriment of beef cattle. Washington D.C.: National Academy Press, 1996. 242 p.

OSORO, K.O. Effecto de las principales variables de manejo sobre los parametros reproductivos en las vacas de cria. Producción y Sanidade Animales, v.1, n.1-2, p.87-111, 1986 (separata, 7).

PASCOAL, L.L.; VAZ, F.N. Desmame precoce aos sessenta dias. In: RESTLE, J. (Ed.) Técnicas avançadas na recria e engorda de bovinos de corte. Santa Maria: Universidade Federal de Santa Maria, 1997. p.36-50.

PILAU, A.; ROCHA, M.G.; RESTlE, J. et al. Desenvolvimento de bezerras de corte recebendo ou não suplementação energética em pastagem hibernal sob diferentes disponibilidades de forragem. Revista Brasileira de Zootecnia, v.34, n.5, p.1483-1492, 2005.

PILAU, A.; LOBATO, J.F.P. Recria de bezerras com suplementação no outono e pastagem cultivada de inverno. Revista Brasileira de Zootecnia, v.35, n.6, p.2388-2396, 2006. 
POPPI, D.P.; McLENANN, S.R. Protein and energy utilization by ruminants at pasture. Journal of Animal Science, v.73, n.1, p.278-290, 1995.

PÖTTER, B.A.A.; LOBATO, J.F.P. Efeitos de carga animal, pastagem melhorada e idade de desmame no comportamento reprodutivo de vacas primíparas. Revista Brasileira de Zootecnia, v.33, n.1, p.192-202, 2004.

PÖTTER, B.A.A.; LOBATO, J.F.P.; TAROUCO, J.U. Desenvolvimento pós-desmame, escores visuais ao sobreano e características de carcaça de novilhas desmamadas aos 180 dias de idade. Revista Brasileira de Zootecnia, v.33, n.6, p.2114-2122, 2004 (supl. 2).

PÖTTER, L.; LOBATO, J.F.P.; MIELITZ NETO, C.G.A. Análises econômicas de modelos de produção com novilhas de corte primíparas aos dois, três ou quatro anos de idade. Revista Brasileira de Zootecnia, v.29, n.3, p.861-870, 2000.

QUADROS, S.A.F.; LOBATO, J.F.P. Efeitos da lotação animal na produção de leite de vacas de corte primíparas e no desenvolvimento dos seus bezerros. Revista Brasileira de Zootecnia, v.26, n.1, p.27-33, 1997.

RESTlE, J.; POLLI, V.A.; ALVES FILHO, D.C. et al. Desenvolvimento de bovinos de corte de diferentes grupos genéticos desmamados aos 3 ou 7 meses de idade. Revista Brasileira de Zootecnia, v.33, n.3, p.1023-1030, 1999.

RESTLE, J.; VAZ, R.Z.; ALVES FILHO, D.C. et al. Desempenho de vacas Charolês e Nelore desterneiradas aos três ou sete meses. Revista Brasileira de Zootecnia, v.30, n.2, p.499-507, 2001.

RESTLE, J.; PACHECO, P,S.; PASCOAL, L.L. et al. Efeito da pastagem, da produção e composição do leite no desemepnho de bezerros de diferentes grupos genéticos. Revista Brasileira de Zootecnia, v.28, n.5, p.691-703, 2004.

RIBEIRO, E.L.A.; RESTLE, J. Desempenho de terneiros Charolês e Abeerden Angus puros e seus mestiços com Nelore. Pesquisa Agropecuária Brasileira, v.26, n.8, p.1145-1151, 1991.
ROCHA, M.G.; LOBATO, J.F.P. Avaliação do desempenho reprodutivo de novilhas de corte primíparas aos dois de idade Revista Brasileira de Zootecnia, v.31, n.3, p.1388-1395, 2002 (supl.).

ROCHA, M.G.; RESTlE, J.; PILAU, A. et al Produção animal e retorno econômico da suplementação em pastagem de aveia e azevém. Ciência Rural, v.33, n.3, p.85-93, 2003.

ROSO, C.; RESTLE, J. Aveia preta, triticale e centeio em mistura com azevém. 2. Produtividade animal e retorno econômico. Revista Brasileira de Zootecnia, v.29, n.1, p.25-83, 2000

ROVIRA, J.M. Manejo nutritivo de los rodeos de cria em pastoreo. Montivideo: Hemisfério Sur, 1996. 288p.

SIMEONE, A.; LOBATO, J.F.P. Efeitos da lotação animal em campo nativo e do controle da amamentação no comportamento reprodutivo de vacas de corte primíparas. Revista Brasileira de Zootecnia, v.25, n.6, p.1216-1227, 1996

SIMEONE, A.; TRUJILlO, A.I.; CÓRDOBA, G. et al. Efecto del destete precoz y de dos sistemas de alimentacion post-destete sobre la ganância de peso terneros Hereford hasta los 15 meses de edad. Revista Argentina de Produccion Animal. v.17, n.1, p.58-59, 1997 (supl.1).

SIMEONE, A.; LOBATO, J.F.P. Efeitos da carga animal em campo nativo e do controle da amamentação no desenvolvimento de bezerros mestiços até um ano de idade. Revista Brasileira de Zootecnia, v.27, n.1, p.179-185, 1998

STATISTICAL ANALYSIS SYSTEM - SAS. SAS/STAT user's guide: statistics. 4.ed. Version 6. Cary: 1997. v.2, 943p.

VIEIRA, A.; LOBATO, J.F.P.; TORRES JR., R.A.A. et al. Fatores determinantes do desempenho reprodutivo de vacas Nelore na região dos cerrados do Brasil Central. Revista Brasileira de Zootecnia, v.34, n.6, p.2408-2416, 2005 (supl.)

VIEIRA, A.; LOBATO, J.F.P.; CORREA, E.S. et al. Desenvolvimento e desempenho reprodutivo de novilhas Nelore criadas a pasto nos cerrados do Centro-Oeste brasileiro. Revista Brasileira de Zootecnia, v.35, n.1, p.186-192, 2006. 